\title{
Fractional Integration and the Business cycle
}

Citation for published version (APA):

Candelon, B., \& Gil-Alana, L. A. (2004). Fractional Integration and the Business cycle. Empirical Economics, 29, 343-359. https://doi.org/10.1007/s00181-003-0171-7

Document status and date:

Published: 01/01/2004

DOI:

10.1007/s00181-003-0171-7

Document Version:

Publisher's PDF, also known as Version of record

\section{Please check the document version of this publication:}

- A submitted manuscript is the version of the article upon submission and before peer-review. There can be important differences between the submitted version and the official published version of record.

People interested in the research are advised to contact the author for the final version of the publication, or visit the DOI to the publisher's website.

- The final author version and the galley proof are versions of the publication after peer review.

- The final published version features the final layout of the paper including the volume, issue and page numbers.

Link to publication

\footnotetext{
General rights rights.

- You may freely distribute the URL identifying the publication in the public portal. please follow below link for the End User Agreement:

www.umlib.nl/taverne-license

Take down policy

If you believe that this document breaches copyright please contact us at:

repository@maastrichtuniversity.nl

providing details and we will investigate your claim.
}

Copyright and moral rights for the publications made accessible in the public portal are retained by the authors and/or other copyright owners and it is a condition of accessing publications that users recognise and abide by the legal requirements associated with these

- Users may download and print one copy of any publication from the public portal for the purpose of private study or research.

- You may not further distribute the material or use it for any profit-making activity or commercial gain

If the publication is distributed under the terms of Article $25 \mathrm{fa}$ of the Dutch Copyright Act, indicated by the "Taverne" license above, 


\title{
Fractional integration and business cycle features
}

\author{
Bertrand Candelon $^{1}$, Luis A. Gil-Alana ${ }^{2}$ \\ ${ }^{1}$ Maastricht University, Department of Economics, 6200 MD Maastricht, The Netherlands \\ ${ }^{2}$ University of Navarre, Department of Economics, 31080 Pamplona, Spain \\ (e-mail: alana@unav.es)
}

First version received: February 2002/Final version received: December 2002

\begin{abstract}
We show in this article that fractionally integrated univariate models for GDP lead to a better replication of the main business cycle characteristics. We firstly show that the business cycle features are clearly affected by the degree of integration as well as by the other short run (AR, MA, etc.) components of the series. Then, we model the real GDP in the UK and the US by means of fractionally ARIMA (ARFIMA) model, and show that the time series can be specified in terms of this type of model with orders of integration higher than one but smaller than two. Comparing the ARFIMA specifications with those based on ARIMA models, we show via simulations that the former better describe the business cycles features of the data.
\end{abstract}

Key words: Long memory, business cycles, fractional integration

JEL classification: $\mathrm{C} 12, \mathrm{C} 15, \mathrm{C} 22$

\section{Introduction}

With the development of the National Bureau of Economic Research (NBER)'s project of "Measurement without Theory" and the first extensive study of Burns and Mitchell (1947) on the American Economy, business cycles and their features have constituted a direct object of empirical analysis. Numerous studies have tried to describe them and to consider their stability over time. Romer (1986, 1994), Diebold and Rudebush (1992) and Watson

The authors want to thank two anonymous referees for wise remarks. We have also benefited from questions and comments of the attendances at the econometric seminar of the Humboldt Universität zu Berlin and the ESEM2001 congress in Lausanne. Remaining errors and omissions are ours. All correspondence to: Luis A. Gil-Alana. 
(1994) have, for example, explored data to know if fluctuations have been smoother (lower amplitude and longer duration) after the Second World War. Also, Neftci (1983), Hamilton (1989), Beaudry and Koop (1993) investigated new business cycles features ${ }^{1}$, showing that cycles exhibit an asymmetry in their phases: recessions being deeper and shorter than expansions.

Recently, business cycle features have been used for another purposes. Candelon and Hénin (1995) characterised the distributions of these features via bootstrapped simulation of simple linear (ARIMA) models for GDP. They could then locate the observed features of the last cycle and conclude that they are rather normal. A step further, Hess and Iwata (1997) used them as benchmarks to gauge the adequacy of macroeconomic stochastic time series models. They replicate via Monte-Carlo simulations different models for GDP. Then, they build for each model the distribution of the business cycle features and compare them to the historical business cycle characteristics. The best model is selected as the one which replicates the best historical features. Three types of linear models, namely, integrating a stochastic trend (ARIMA), a deterministic trend and a segmented trend (as in Perron 1989) as well as several non linear ones (SETAR, Markov-Switching and Beaudry and Koop 1993) are considered. They conclude that complex non-linear or linear models do not better replicate business cycle features than a simple linear ARIMA(1,1,0). Such a conclusion appears to be rather destructive for recent attempts, which have tried to better model GDP.

Nevertheless, they do not consider a recent and growing literature, which tries to model GDP and other macroeconomic time series in terms of fractionally integrated processes. Examples are Diebold and Rudebusch (1989), Sowell (1992), Gil-Alana and Robinson (1997), etc. A proper definition of fractional integration will be given in Sect. 2. We can, however, mention here that the ARIMA model can be viewed as a particular case of a much more general class of models, called fractionally ARIMA (ARFIMA), in which we allow for a fractional degree of differencing in a given raw time series.

In this article, we show that the ARFIMA models can better describe the business cycle characteristics of the GDP in the UK and the US, compared with the ARIMA specifications as well as other approaches. The structure of the paper is as follows: Sect. 2 briefly describes the concepts of fractional integration and business cycles. Section 3 shows with some simulations that the degree of fractional integration of an univariate model affects to the characteristics of the fluctuations. Section 4 uses both ARIMA and ARFIMA models to describe the behaviour of the GDP series. Section 5 compares both types of models in terms of business cycle features while Sect. 6 concludes.

\section{Fractional integration and business cycle characteristics}

For the purpose of the present paper, we define an $\mathrm{I}(0)$ process $\left\{u_{t}, t=0, \pm 1, \ldots\right\}$ as a covariance stationary process with spectral density function that is positive and finite at the zero frequency. In this context, we say that $x_{\mathrm{t}}$ is $\mathrm{I}(\mathrm{d})$ if

\footnotetext{
${ }^{1}$ These features integrate the third moment of the cycle as well as the conditional asymmetry in mean.
} 


$$
(1-L)^{d} x_{t}=u_{t}, \quad t=1,2, \ldots,
$$

where $\mathrm{L}$ is the lag operator $\left(L x_{\mathrm{t}}=x_{\mathrm{t}-1}\right)$, and $\mathrm{d}$ can be any real number. The macroeconomic literature stresses the cases of $d=0$ and $d=1$, and this has been used, for example, to determine if shocks in output fluctuations are temporary (Blanchard 1981; Clark 1987; Lam 1990) or permanent (Nelson and Plosser 1982; Campbell and Mankiw 1987; Hamilton 1989). In the later case, we say that $x_{\mathrm{t}}$ follows a unit root process or that the model contains a stochastic trend. This model became popular after the paper of Nelson and Plosser (1982), who following the work and ideas of Box and Jenkins (1970), showed that many US macroeconomic series could be specified in terms of unit roots. A huge amount of empirical work has followed this approach (eg., Stock and Watson 1986; Diebold and Nerlove 1989; etc.). However, as it shown by Adenstedt (1974), Taqqu (1975) and subsequent work, d can also be a real number. When $d=0$ in (1), $x_{\mathrm{t}}=u_{\mathrm{t}}$, and a weakly autocorrelated $x_{\mathrm{t}}$ is allowed for. However, if $d>0, x_{\mathrm{t}}$ is said to be long memory, so-called because of the strong association between observations widely separated in time. Note that the polynomial in (1) can be expanded in terms of its Binomial expansion, such that for all real $d$,

$$
(1-L)^{d}=\sum_{j=1}^{\infty} \frac{\Gamma(d+1)(-1)^{j}}{\Gamma(d-j+1) \Gamma(j+1)}=1-d L+\frac{d(d-1)}{2}-\ldots,
$$

where $\Gamma(\mathrm{x})$ means the gamma function. This type of process was initially proposed by Granger (1980, 1981), Hosking (1981) and they were theoretically justified in terms of aggregation by Robinson (1978), Granger (1980). Similarly Croczeck-Georges and Mandelbrot (1995), Taqqu et al. (1997), Chambers (1998) and Lippi and Zaffaroni (1999) also use aggregation to motivate long memory processes, while Parke (1999) uses a closely related discrete time error duration model. There is an interest in the estimation and testing of the fractional differencing parameter. If $d \in(0,0.5), x_{\mathrm{t}}$ in (1) is covariance stationary while $d \in(0.5,1)$ will imply that the series is nonstationary but still mean reverting, with the effect of the shocks dying away in the long run. On the contrary, if $d \geq 1$, the process will be nonstationary and non-mean reverting, with the effects of the shocks persisting forever. Thus, for example, if $d>1$ and the data are in logs, that means that the growth rates have a long memory component and therefore, the stochastic trend overcome other potential characteristics of the series, In other words, the fractional differencing parameter can be used as an indicator of the degree of persistence of the series and, higher $d$ is, higher will be the degree of persistence, implying that the cycles are less likely to occur. Examples of long memory processes in economic growth are among others Silverberg and Verspagen (1999) and Michelacci and Zaffaroni (2000).

Let us assume now that $u_{\mathrm{t}}$ in (1) is a stationary $\operatorname{ARMA}(\mathrm{p}, \mathrm{q})$ process of form:

$$
\phi_{p}(L) u_{t}=\theta_{q}(L) \varepsilon_{t}, \quad t=1,2, \ldots,
$$

where $\phi_{\mathrm{p}}(L)=\left(1-\phi_{1} \mathrm{~L}-\ldots-\phi_{\mathrm{p}} \mathrm{L}^{\mathrm{p}}\right), \theta_{\mathrm{q}}(L)=\left(1+\theta_{1} L+\ldots+\theta_{\mathrm{q}} \mathrm{L}^{\mathrm{q}}\right)$, and white noise $\varepsilon_{\mathrm{t}}$. Substituting (2) in (1), the general time series model becomes

$$
\phi_{p}(L)(1-L)^{d} x_{t}=\theta_{q}(L) \varepsilon_{t}, \quad t=1,2, \ldots,
$$


which is usually called an $\operatorname{ARFIMA}(\mathrm{p}, \mathrm{d}, \mathrm{q})$ model. Assuming that the innovations are normal, Sowell (1992) estimated the parameters in (3) using a procedure that allows quick evaluation of the likelihood function in the time domain, which is given by

$$
(2 \pi)^{-T / 2}|\Sigma|^{-1 / 2} \exp \left\{-\frac{1}{2} X_{T}^{\prime} \Sigma^{-1} X_{T}\right\},
$$

with $X_{\mathrm{T}}=\left(x_{1}, \ldots, x_{\mathrm{T}}\right)^{\prime} \sim N(0, \Sigma)$. Other parametric methods of estimating $\mathrm{d}$ based on the frequency domain were proposed among others by Fox and Taqqu (1986) and Dahlhaus (1989). Small sample properties of these and other estimates were examined in Smith et al. (1997) and Hauser (1999). In the first of these articles, they compare several semi-parametric procedures with the maximum likelihood estimation method of Sowell (1992), finding that the Sowell's (1992) procedure outperforms the semi-parametric ones in term of the bias and the mean squared errors. Hauser (1999) also compares the Sowell's (1992) procedure with others based on the exact and the Whittle likelihood function in the time and in the frequency domain and shows that the Sowell's (1992) procedure dominates to the others in case of fractionally integrated models. Furthermore, we use the Sowell's (1992) estimation method in the empirical application in Sect. 4, because of the simplicity in the calculations that it affords through Ox (see, Doornik and Ooms 1990). Also, Robinson (1994) proposed a Lagrange Multiplier (LM) test of the null hypothesis:

$$
H_{o}: d=d_{o},
$$

in (1) for any real value $d_{\mathrm{o}}$. Specifically, the test statistic is given by:

$$
\hat{r}=\left(\frac{T}{\hat{A}}\right)^{1 / 2} \frac{\hat{a}}{\hat{\sigma}^{2}},
$$

where

$$
\begin{aligned}
& \hat{a}=\frac{-2 \pi}{T} \sum_{j=1}^{T-1} \psi\left(\lambda_{j}\right) g\left(\lambda_{j} ; \hat{\tau}\right)^{-1} I\left(\lambda_{j}\right) ; \quad \hat{\sigma}^{2}=\frac{2 \pi}{T} \sum_{j=1}^{T-1} g\left(\lambda_{j} ; \hat{\tau}\right)^{-1} I\left(\lambda_{j}\right) ; \\
& \hat{A}=\frac{2}{T}\left(\sum_{j=1}^{T-1} \psi\left(\lambda_{j}\right)^{2}-\sum_{j=1}^{T-1} \psi\left(\lambda_{j}\right) \hat{\varepsilon}\left(\lambda_{j}\right)^{\prime} \times\left(\sum_{j=1}^{T-1} \hat{\varepsilon}\left(\lambda_{j}\right) \hat{\varepsilon}\left(\lambda_{j}\right)^{\prime}\right)^{-1} \times \sum_{j=1}^{T-1} \hat{\varepsilon}\left(\lambda_{j}\right) \psi\left(\lambda_{j}\right)\right) \\
& \psi\left(\lambda_{j}\right)=\log \left|2 \sin \frac{\lambda_{j}}{2}\right| ; \quad \hat{\varepsilon}\left(\lambda_{j}\right)=\frac{\partial}{\partial \tau} \log g\left(\lambda_{j} ; \hat{\tau}\right) ; \quad \lambda_{j}=\frac{2 \pi j}{T} .
\end{aligned}
$$

$\mathrm{I}\left(\lambda_{\mathrm{j}}\right)$ is the periodogram of $\hat{u}_{t}$ where $\hat{u}_{t}=(1-L)^{d_{o}} y_{t}$ and $\mathrm{g}$ above is a known function coming from the spectral density of $u_{\mathrm{t}}: f(\lambda ; \tau)=\frac{\sigma^{2}}{2 \pi} g(\lambda ; \tau)$, evaluated at $\hat{\tau}=\arg \min \sigma^{2}(\tau)$. Based on $\mathrm{H}_{\mathrm{o}}$ (4), Robinson (1994) showed that under certain regularity conditions,

$$
\hat{r} \rightarrow{ }_{d} N(0,1) \quad \text { as } \quad T \rightarrow \infty .
$$

Thus, an approximate $100 \alpha \%$ level test of (4) will reject $\mathrm{H}_{\mathrm{o}}$ against the alternative: $H_{\mathrm{a}}: d>d_{0}\left(d<d_{0}\right)$ if $\hat{r}>z_{\alpha}\left(\hat{r}<-z_{\alpha}\right)$, where the probability that 
a standard normal variate exceeds $\mathrm{z}_{\alpha}$ is $\alpha$. He also showed that the tests are efficient in the Pitman sense, i.e., that against local alternatives of form: $H_{\mathrm{a}}$ : $d=d_{\mathrm{o}}+\delta T^{-1 / 2}$, with $\delta \neq 0, \hat{r}$ has a limit distribution which is normal with variance 1 and mean that cannot (when $u_{\mathrm{t}}$ is Gaussian) be exceeded in absolute value by that of any other rival regular statistic. Empirical applications based on this version of Robinson's (1994) tests can be found in GilAlana and Robinson (1997) and Gil-Alana (2000) and, other versions of his tests based on seasonal, (quarterly and monthly), and cyclical models are respectively Gil-Alana and Robinson (2001) and Gil-Alana (1999, 2001).

We now describe a rule for dating the business cycles and define their characteristics. Numerous methods have been proposed in the literature. They can be based on direct data analysis (Burns and Mitchell 1947), on expert judgment (NBER) or rely on the most recent econometric methods (Hamilton 1994) ${ }^{2}$. In this paper, we have decided to consider exclusively classical cycles (directly extracted from the data in levels) in order to avoid statistical problems caused by the extraction of the cyclical component (see Canova 1994). Besides, we apply the most common rule to date classical business cycles. It is at the basis of the famous program developed by Bry and Boscham (1971) and defines the phases of the business cycles as follows: ${ }^{3}$

a) $y_{t-2}>y_{t-1}>y_{t}<y_{t+1}$, then there is a trough in t, where $y_{t}$ is, for example, the GDP in levels.

b) $y_{t-2}<y_{t-1}<y_{t}>y_{t+1}$ then there is a peak in $\mathrm{t}$.

c) When several identical turning points are detected consecutively, we retain the optimal one (i.e., the highest peak and the deepest trough).

This rule is very intuitive because it simply considers that a turning point occurs after two consecutive periods of expansion and recession. Such a rule consists of detecting a change in the slope of the process: Condition a) and b) can be respectively rewritten as $\Delta_{\mathrm{j}} \mathrm{y}_{\mathrm{t}-\mathrm{j}}>0$ and $\Delta_{\mathrm{j}}, \mathrm{y}_{\mathrm{t}+\mathrm{j}},<0$, with $j=2$ and $j^{\prime}=1$ for a peak (respectively as $\Delta_{\mathrm{j}} \mathrm{y}_{\mathrm{t}-\mathrm{j}}<0$ and $\Delta_{\mathrm{j}}, \mathrm{y}_{\mathrm{t}+\mathrm{j}},>0$ for a trough). Such a definition insures that phases of the cycles have a minimum duration of 2 quarters and the completed cycles a minimum length of one year. It also presents the advantage to induce an asymmetry in the length of the cycle phase. This is especially the case when the generated process is $\mathrm{I}(\mathrm{d})$ with $d \geq 1$. As there is no mean-reversion, economic activity has a stochastic growth rate and the length of an expansion is longer than the duration of a recession. This property is more difficult to exhibit from growth cycles (extracted from filtered data ${ }^{4}$ ) but is confirmed in historical data (Moore and Zarnowitz 1982). On the contrary, we can not expect to detect an asymmetry in the amplitude of the phases, as the conditions on the change in slope is symmetric for troughs and peaks.

\footnotetext{
${ }^{2}$ See Pagan and Harding, 1999 for an exhaustive survey of the procedures for determining turning points.

${ }^{3}$ The same method can also be used on filtered data to exhibit growth cycles (see Canova 1994).

${ }^{4}$ Canova (1994) has shown that the filter used to extract growth cycles has an impact on the business cycle definition and thus affects to their features. Hence, a classical approach of the business cycle is adopted in the sequel of the paper.
} 


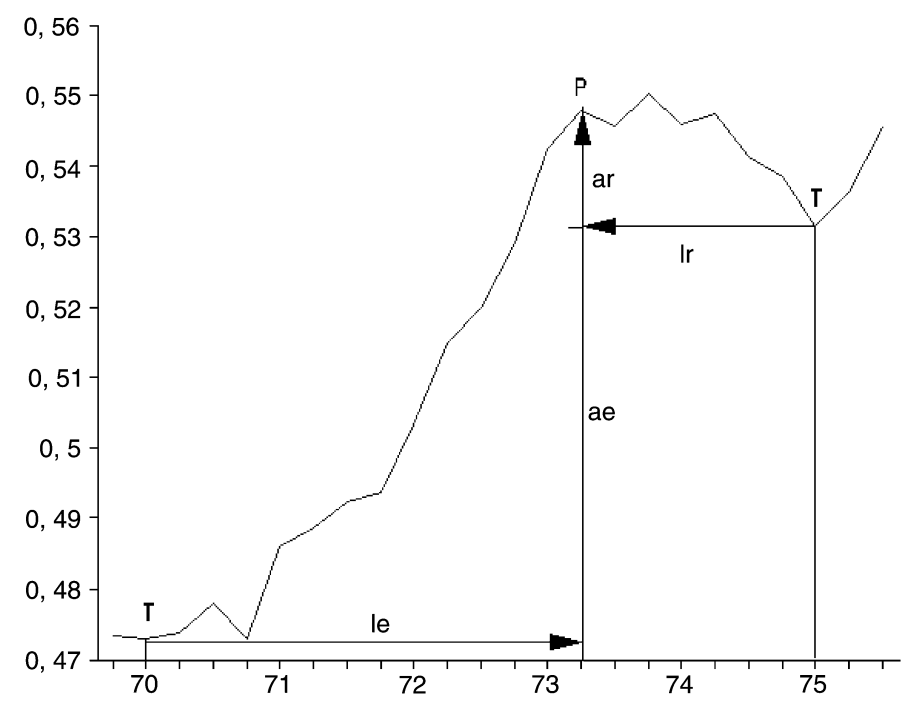

Fig. 1. Business cycle features. Note: This figure represents the first cycle in US data. T stands for Trough, $\mathrm{P}$ for Peak, le for length of expansion, lr for length of recession, ae for amplitude of expansion and ar for amplitude of recession. The length of the cycle is the sum of the two lengths

This method has been criticised in the few years: For example, it could exhibit not only major but also minor cycles. McNees (1991) and Webb (1991) propose to solve this problem via an increase in the reference period (for example, a peak could be characterized by 3 consecutive periods of growth over a year period). Candelon and Hénin (1995) have also noticed that this method leads to slight differences with the algorithms based on the detection of local optimum in the cases of growth cycles. ${ }^{5}$ However, integrating these extensions in our dating algorithm will not alter the links between the degree of fractional integration and the business cycle characteristics. We thus make the choice of simplicity and keep rules a)-c) as our dating algorithm.

From this dating, we have built five indicators (see Figure 1): the number of peaks (which is linked to the number of $\operatorname{cycles}^{6}$ ), the length of the cycles (period running between two successive troughs), the length and the amplitude of an expansion (period running from a trough to a peak) and the length and the amplitude of a recession (period running from a peak to a trough).

\footnotetext{
${ }^{5}$ A local optimum is not a turning point for our methodology if it is preceded and followed by only one quarter of increase or decrease in the activity.

${ }^{6}$ As we consider the cycle as the fluctuation between two consecutive troughs, the number of peaks is always greater than the number of cycles. When the series begins and ends by a peak, the number of peaks can equal the number of cycles plus 2 (if the series begins and ends by a peak), it can equal the number of cycles plus 1 (if the series begins or ends by a peak) and it can equal the number of cycles (if the series begins and ends by a trough).
} 
Table 1. Business cycle characteristics for fractional processes with white noise disturbances

\begin{tabular}{|c|c|c|c|c|c|c|}
\hline $\begin{array}{l}\text { Sample } \\
\text { size }\end{array}$ & $\begin{array}{l}\text { Values } \\
\text { of } d\end{array}$ & $\begin{array}{l}\text { Aver. } \\
\text { Number } \\
\text { of peaks }\end{array}$ & $\begin{array}{l}\text { Mean length } \\
\text { of recession }\end{array}$ & $\begin{array}{l}\text { Mean length } \\
\text { of expansion }\end{array}$ & $\begin{array}{l}\text { Mean } \\
\text { amplitude of } \\
\text { recession }\end{array}$ & $\begin{array}{l}\text { Mean } \\
\text { amplitude of } \\
\text { expansion }\end{array}$ \\
\hline \multirow[t]{7}{*}{$\mathrm{T}=100$} & 0.00 & $7.37(0.03)$ & $6.29(1.64)$ & $11.01(1.97)$ & $2.24(0.33)$ & $2.24(0.33)$ \\
\hline & 0.25 & $7.76(0.03)$ & $5.94(1.48)$ & $10.46(1.75)$ & $2.16(0.34)$ & $2.16(0.35)$ \\
\hline & 0.50 & $8.07(0.06)$ & $5.73(1.35)$ & $9.83(1.54)$ & $2.15(0.37)$ & $2.15(0.39)$ \\
\hline & 0.75 & $8.17(0.06)$ & $5.68(1.30)$ & $9.48(1.45)$ & $2.27(0.45)$ & $2.36(0.48)$ \\
\hline & 1.00 & $7.69(0.06)$ & $6.15(1.45)$ & $9.63(1.50)$ & $2.79(0.68)$ & $3.00(0.73)$ \\
\hline & 1.50 & $4.43(0.04)$ & $10.41(2.90)$ & $15.11(2.02)$ & $10.37(3.67)$ & $12.02(3.61)$ \\
\hline & 2.00 & $2.66(1.92)$ & $13.00(1.92)$ & $19.39(2.02)$ & $29.12(5.48)$ & $36.84(5.86)$ \\
\hline \multirow[t]{7}{*}{$\mathrm{T}=300$} & 0.00 & $23.30(0.18)$ & $6.22(0.99)$ & $11.09(1.21)$ & $2.24(0.19)$ & $2.24(0.19)$ \\
\hline & 0.25 & $24.64(0.19)$ & $5.92(0.89)$ & $10.37(1.06)$ & $2.16(0.19)$ & $2.16(0.20)$ \\
\hline & 0.50 & $25.55(0.20)$ & $5.72(0.81)$ & $9.91(0.95)$ & $2.16(0.21)$ & $2.17(0.23)$ \\
\hline & 0.75 & $25.79(0.20)$ & $5.70(0.78)$ & $9.52(0.85)$ & $2.29(0.26)$ & $2.35(0.28)$ \\
\hline & 1.00 & $24.30(0.19)$ & $6.10(0.86)$ & $9.64(0.90)$ & $2.77(0.40)$ & $2.95(0.43)$ \\
\hline & 1.50 & $12.35(0.11)$ & $12.21(3.85)$ & $18.86(4.39)$ & $13.73(6.22)$ & $19.13(7.53)$ \\
\hline & 2.00 & $3.82(0.04)$ & $26.04(8.01)$ & $44.10(9.66)$ & $114.77(44.12)$ & $177.19(51.54)$ \\
\hline \multirow[t]{7}{*}{$\mathrm{T}=500$} & 0.00 & $39.33(0.15)$ & $6.24(0.78)$ & $11.08(0.94)$ & $2.25(0.15)$ & $2.25(0.15)$ \\
\hline & 0.25 & $41.38(0.33)$ & $5.97(0.70)$ & $10.22(0.82)$ & $2.17(0.15)$ & $2.17(0.15)$ \\
\hline & 0.50 & $43.11(0.34)$ & $5.73(0.63)$ & $9.76(0.72)$ & $2.16(0.16)$ & $2.18(0.17)$ \\
\hline & 0.75 & $43.68(0.34)$ & $5.64(0.59)$ & $9.51(0.67)$ & $2.28(0.20)$ & $2.35(0.21)$ \\
\hline & 1.00 & $41.07(0.32)$ & $6.07(0.66)$ & $9.67(0.70)$ & $2.76(0.31)$ & $2.95(0.33)$ \\
\hline & 1.50 & $19.92(0.18)$ & $13.07(3.70)$ & $19.47(4.06)$ & $15.81(6.64)$ & 20.77 (7.62) \\
\hline & 2.00 & $4.63(0.05)$ & $33.54(12.24)$ & $61.70(16.84)$ & $196.67(85.03)$ & $336.16(122.33)$ \\
\hline
\end{tabular}

Note: We perform 2500 replications. Standard errors in parenthesis.

\section{A simulation study}

We explore in this section the link between the degree of fractional integration and business cycle features via simulations. To this goal, we consider a process $\left\{y_{\mathrm{t}}\right\}_{\mathrm{t}=1 \ldots \mathrm{T}}$, with the following DGP: $(1-L)^{\mathrm{d}} y_{\mathrm{t}}=u_{\mathrm{t}}$. According to the values taken by $\mathrm{d}, \mathrm{y}_{\mathrm{t}}$ can be stationary $(d<0.5)$, or non-stationary $(d \geq 0.5)$. To analyse the effect of $d$ on the business cycle features, we simulate 2500 series of length 100,300 and 500 , for some values of $d=\{0,0.25,0.5,0.75,1$, $1.5,2\}$ and then compute the mean and the variance of the five pre-defined features of the cycle (number of cycles, length and amplitude of the phase of the cycles) ${ }^{7}$. The results could indeed be affected by the process followed by $\mathrm{u}_{\mathrm{t}}$. Thus, as in Hess and Iwata (1997), three different linear processes are considered:

1. $u_{\mathrm{t}}$ is a white noise $\mathrm{N}(0,1)$. Results are gathered in Table 1 .

2. $u_{\mathrm{t}}=\phi u_{\mathrm{t}-1}+\varepsilon_{\mathrm{t}}$, (AR1). Results for $\phi=\{0.25,0.5,0.75\}$ are gathered in Table 2 .

3. $u_{\mathrm{t}}=\varepsilon_{\mathrm{t}}+\theta \varepsilon_{\mathrm{t}-1}$, (MA1). Results for $\theta=\{0.25,0.5,0.75\}$ are gathered in Table 3.

\footnotetext{
${ }^{7}$ The complete distribution of these features could be computed as in Hess and Iwata (1997). However, as all processes are linear, the distribution will not give more information than the mean and the variance.
} 
Table 2. Business cycle characteristics for fractional processes with $A R(1)$ disturbances and $\mathrm{T}=300$

\begin{tabular}{|c|c|c|c|c|c|c|}
\hline $\begin{array}{l}\text { Sample } \\
\text { size }\end{array}$ & $\begin{array}{l}\text { Values } \\
\text { of } d\end{array}$ & $\begin{array}{l}\text { Aver. } \\
\text { number } \\
\text { of peaks }\end{array}$ & $\begin{array}{l}\text { Mean length } \\
\text { of recession }\end{array}$ & $\begin{array}{l}\text { Mean length } \\
\text { of expansion }\end{array}$ & $\begin{array}{l}\text { Mean } \\
\text { amplitude of } \\
\text { recession }\end{array}$ & $\begin{array}{l}\text { Mean } \\
\text { amplitude of } \\
\text { expansion }\end{array}$ \\
\hline \multirow[t]{7}{*}{$\phi=0.25$} & 0.00 & $26.12(0.20)$ & $5.66(0.82)$ & $9.62(0.94)$ & $2.28(0.19)$ & $2.29(0.20)$ \\
\hline & 0.25 & $27.28(0.21)$ & $5.34(0.72)$ & $9.48(0.85)$ & $2.26(0.21)$ & $2.27(0.22)$ \\
\hline & 0.50 & $27.92(0.22)$ & $5.25(0.66)$ & $9.02(0.75)$ & $2.33(0.24)$ & $2.37(0.25)$ \\
\hline & 0.75 & $27.10(0.21)$ & $5.38(0.67)$ & $9.20(0.75)$ & $2.60(0.31)$ & $2.72(0.34)$ \\
\hline & 1.00 & $24.51(0.19)$ & $5.95(0.82)$ & $9.91(0.90)$ & $3.35(0.53)$ & $3.73(0.58)$ \\
\hline & 1.50 & $11.53(0.11)$ & $12.91(4.21)$ & $21.61(5.07)$ & $19.35(8.89)$ & $28.93(11.06)$ \\
\hline & 2.00 & $3.75(0.04)$ & $27.38(7.90)$ & $44.55(9.91)$ & $157.92(56.34)$ & $223.80(68.04)$ \\
\hline \multirow[t]{7}{*}{$\phi=0.50$} & 0.00 & $27.88(0.22)$ & $5.25(0.68)$ & $9.17(0.80)$ & $2.34(0.21)$ & $2.34(0.22)$ \\
\hline & 0.25 & $28.36(0.22)$ & $5.18(0.63)$ & $8.91(0.71)$ & $2.42(0.24)$ & $2.45(0.25)$ \\
\hline & 0.50 & $27.78(0.22)$ & $5.22(0.62)$ & $9.15(0.71)$ & $2.64(0.30)$ & $2.73(0.32)$ \\
\hline & 0.75 & $25.87(0.20)$ & $5.63(0.71)$ & $9.57(0.79)$ & $3.22(0.45)$ & $3.46(0.49)$ \\
\hline & 1.00 & $22.28(0.17)$ & $6.62(1.00)$ & $10.82(1.08)$ & $4.71(0.90)$ & $5.37(0.98)$ \\
\hline & 1.50 & $9.54(0.09)$ & $15.82(5.42)$ & $26.83(6.52)$ & $35.61(16.41)$ & $51.23(19.83)$ \\
\hline & 2.00 & $3.32(9.03)$ & $30.27(7.93)$ & $50.28(9.22)$ & $264.89(83.44)$ & 363.07 (93.09) \\
\hline \multirow[t]{7}{*}{$\phi=0.75$} & 0.00 & $27.41(0.21)$ & $5.32(0.66)$ & $9.23(0.76)$ & $2.44(0.25)$ & $2.47(0.27)$ \\
\hline & 0.25 & $26.76(0.21)$ & $5.40(0.66)$ & $9.57(0.77)$ & $2.72(0.33)$ & $2.82(0.35)$ \\
\hline & 0.50 & $24.79(0.19)$ & $5.84(0.75)$ & $10.18(0.86)$ & $3.39(0.50)$ & $3.66(0.54)$ \\
\hline & 0.75 & $21.39(0.17)$ & $6.82(1.03)$ & $11.62(1.17)$ & $4.91(0.96)$ & $5.60(1.03)$ \\
\hline & 1.00 & $16.83(0.13)$ & 8.60 (1.67) & $14.85(1.96)$ & $8.84(2.38)$ & $11.11(2.67)$ \\
\hline & 1.50 & $6.42(0.06)$ & $22.15(8.06)$ & $40.25(1.96)$ & $88.09(41.56)$ & $136.14(51.08)$ \\
\hline & 2.00 & $2.91(0.03)$ & $33.41(6.43)$ & $60.58(8.20)$ & $531.91(124.68)$ & $842.48(153.26)$ \\
\hline
\end{tabular}

Note: We perform 2500 replications. Standard errors in parenthesis.

To have a more precise view, Fig. 2 plots the results for white noise $u_{t}$. We observe that the average length of expansion is in all the cases greater than the duration of the recession, which is consistent with most of empirical findings in the literature ${ }^{8}$. The tables also confirm that the amplitude of the phase is symmetrical: Recession amplitudes seem to be higher than expansion ones, but the variance is such that the symmetry cannot be rejected. It also turns out that the relationship between the degree of fractional integration and the business cycle features has the same evolution in all cases. The average number of peaks increases until a value of $\mathrm{d}$ around 0.5 and then goes down. The other features dealing with the length and the amplitude of the phases exhibit an opposite evolution. At the light of footnote 6 , it is also not surprising to find larger simulated numbers of periods (obtained by multiplying the number of peaks by the mean length of expansion plus the mean length of recession) than the number of observations. The variance of the features exhibits similar paths. These results can be interpreted in the following way: When the degree of integration increases, the mean reversion is less important. A large part of the dynamic of $y_{t}$ is then impulsed by the stochastic trend. The variance and the mean of the process are thus higher, leading a smaller number of longer and deeper business cycles. For the extreme case

\footnotetext{
${ }^{8}$ This asymmetry might be a consequence of our dating algorithm, though it might also be due to the stochastic trend of the generated series.
} 
Table 3. Business cycle characteristics for fractional processes with MA(1) disturbances and $\mathrm{T}=300$

\begin{tabular}{lllcccc}
\hline \hline $\begin{array}{l}\text { Sample } \\
\text { size }\end{array}$ & $\begin{array}{l}\text { Values } \\
\text { of d }\end{array}$ & $\begin{array}{l}\text { Aver. } \\
\text { number } \\
\text { of peaks }\end{array}$ & $\begin{array}{l}\text { Mean length } \\
\text { of recession }\end{array}$ & $\begin{array}{l}\text { Mean length } \\
\text { of expansion }\end{array}$ & $\begin{array}{l}\text { Mean } \\
\text { amplitude } \\
\text { of recession }\end{array}$ & $\begin{array}{l}\text { Mean } \\
\text { amplitude of } \\
\text { expansion }\end{array}$ \\
\hline$\theta=0.25$ & 0.00 & $27.38(0.21)$ & $5.34(0.74)$ & $9.36(0.88)$ & $2.33(0.19)$ & $2.33(0.19)$ \\
& 0.25 & $28.52(0.22)$ & $5.09(0.66)$ & $9.05(0.78)$ & $2.29(0.20)$ & $2.30(0.21)$ \\
& 0.50 & $29.16(0.23)$ & $4.97(0.60)$ & $8.83(0.71)$ & $2.33(0.22)$ & $2.36(0.24)$ \\
& 0.75 & $28.39(0.22)$ & $5.13(0.62)$ & $8.82(0.70)$ & $2.54(0.29)$ & $2.65(0.31)$ \\
& 1.00 & $25.83(0.20)$ & $5.72(0.76)$ & $9.31(0.81)$ & $3.21(0.48)$ & $3.49(0.52)$ \\
& 1.50 & $12.13(0.11)$ & $12.64(4.24)$ & $20.25(4.80)$ & $18.46(8.73)$ & $25.75(10.15)$ \\
& 2.00 & $3.84(0.04)$ & $24.79(7.32)$ & $42.11(9.01)$ & $130.87(47.07)$ & $197.12(57.26)$ \\
0.50 & 0.00 & $32.33(0.25)$ & $4.52(0.53)$ & $8.02(0.61)$ & $2.48(0.19)$ & $2.48(0.19)$ \\
& 0.25 & $33.01(0.26)$ & $4.42(0.48)$ & $7.82(0.55)$ & $2.47(0.20)$ & $2.47(0.22)$ \\
& 0.50 & $32.65(0.25)$ & $4.46(0.48)$ & $7.88(0.54)$ & $2.55(0.24)$ & $2.60(0.26)$ \\
& 0.75 & $30.95(0.24)$ & $4.72(0.52)$ & $8.21(0.58)$ & $2.86(0.32)$ & $2.99(0.35)$ \\
& 1.00 & $27.32(0.21)$ & $5.35(0.69)$ & $9.13(0.77)$ & $3.68(0.56)$ & $4.11(0.62)$ \\
& 1.50 & $12.37(0.11)$ & $12.74(4.31)$ & $20.70(4.96)$ & $22.77(10.65)$ & $32.14(12.71)$ \\
& 2.00 & $3.83(0.04)$ & $25.55(7.55)$ & $44.90(10.15)$ & $169.58(60.35)$ & $273.02(81.86)$ \\
$0=0.75$ & 0.00 & $36.14(0.28)$ & $4.04(0.41)$ & $7.25(0.47)$ & $2.69(0.20)$ & $2.69(0.20)$ \\
& 0.25 & $36.13(0.28)$ & $4.07(0.40)$ & $7.05(0.44)$ & $2.71(0.22)$ & $2.72(0.23)$ \\
& 0.50 & $34.94(0.27)$ & $4.18(0.41)$ & $7.44(0.46)$ & $2.85(0.26)$ & $2.90(0.26)$ \\
& 0.75 & $32.52(0.25)$ & $4.53(0.48)$ & $7.76(0.53)$ & $3.22(0.36)$ & $3.39(0.39)$ \\
& 1.00 & $28.32(0.22)$ & $5.18(0.66)$ & $8.88(0.73)$ & $4.18(0.64)$ & $4.71(0.70)$ \\
& 1.50 & $12.46(0.11)$ & $12.23(4.15)$ & $20.54(4.92)$ & $25.05(11.84)$ & $36.50(14.54)$ \\
& 2.00 & $3.79(0.04)$ & $25.51(7.23)$ & $47.07(10.31)$ & $197.69(69.00)$ & $328.39(97.74)$ \\
\hline
\end{tabular}

Note: We perform 2500 replications. Standard errors in parenthesis.

where $\mathrm{d}$ tends to infinite, the process is exclusively driven by the trend and no more cycles could be extracted. Figure 2 also shows that the level of inflection is quicker for the amplitude characteristics $(d \sim 0.25$ for white noise and $d \sim 0.5$ for $\mathrm{AR}$ and MA $\left.u_{\mathrm{t}}\right)$ and a little bit longer for the duration ones ( $d \sim 0.75$ for white noise). It also appears that if $d>1$, the path is explosive (for 300 observations, we only find a mean value of 4 cycles for a white noise $u_{\mathrm{t}}$ and $d=2$, whereas when $d=1,24$ peaks can be observed on average).

When the AR or the MA coefficients become high (Tables 2 and 3), the evolution of the features with respect to the degree of fractional integration becomes linear: with a negative slope for the number of cycles and a positive one for the other criterion. When $\phi$ is closed to one, the process possesses a near-unit-root, removing the mean reversion and increasing the variance. The average number of cycles is thus smaller, whereas their length and amplitude become higher, $\phi$ thus playing a similar role as the degree of integration.

\section{The empirical application}

The time series data analysed in this section correspond to the logarithmic transformation of the real Gross Domestic Product (GDP) in the United Kingdom and the United States, quarterly, (seasonally adjusted), for the time period 1961:1-2000:1, (i.e., $T=157$ ), and are extracted from the IMF-IFS database. We have performed our dating algorithm and compared its results 
Mean length of recession

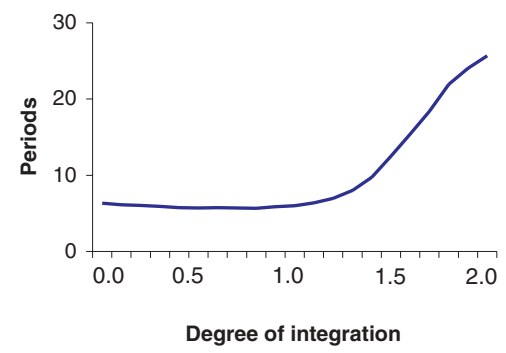

Mean amplitude of recession

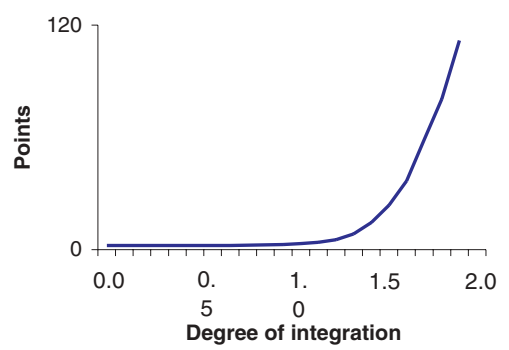

Mean length of expansion

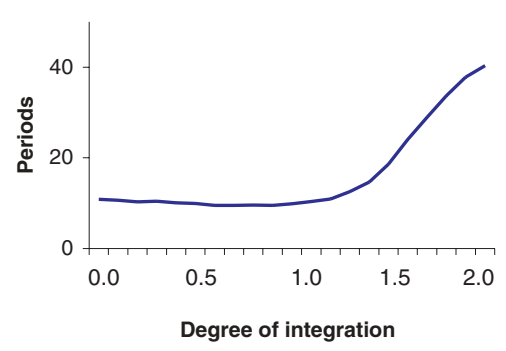

Mean amplitude of expansion

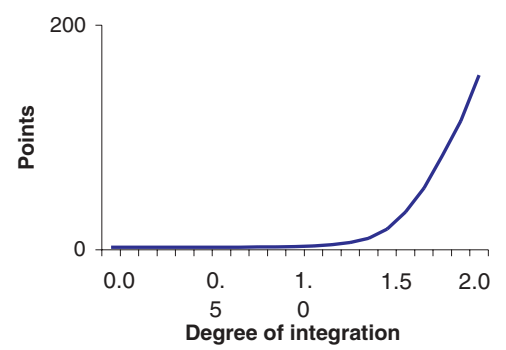

Average number of peaks

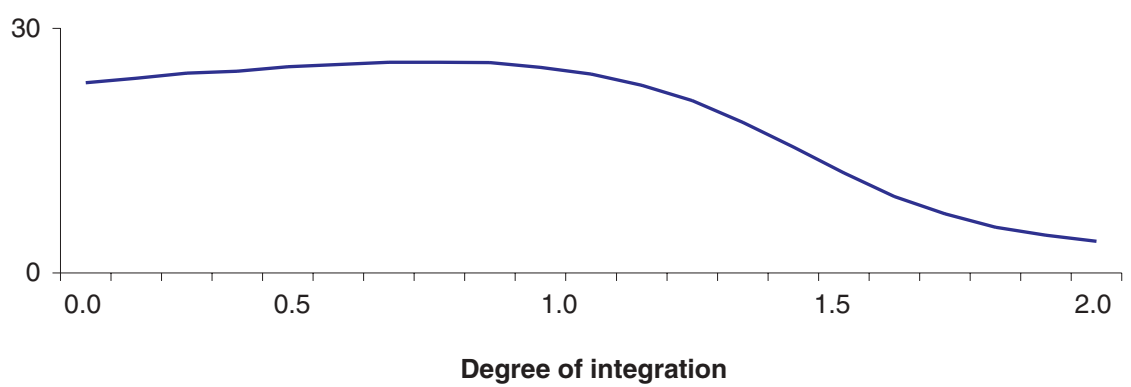

Fig. 2. Note: We perform 2500 replications of process 1 ( $\mathrm{u}_{\mathrm{t}}$ is a white noise). The sample length is 300 observations

with reference studies. For the United States, it is referred to the National Bureau of Economic Research (NBER) business cycle dating. It turns out in Table 4 that our algorithm leads to a nearly identical ${ }^{9}$ dating except for the cycle (80:3-81:1), which is considered as minor in the official dating. For the UK, as it exists no official dating, we refer to the paper of Artis et al. (1997). Our results are similar but not identical. Nevertheless, it is worth noticing that

\footnotetext{
${ }^{9}$ As NBER dating is performed for monthly data and our for quarterly observations, sometimes our dating differs from a quarter.
} 
Table 4. Business cycle dating

\begin{tabular}{|c|c|c|c|c|}
\hline \multirow[t]{2}{*}{ Country } & \multicolumn{2}{|c|}{ Our dating } & \multicolumn{2}{|c|}{ Reference dating* } \\
\hline & Peak & Trough & Peak & Trough \\
\hline United Kingdom & $\begin{array}{l}64: 4 \\
73: 1 \\
78: 4 \\
84: 1 \\
90: 2\end{array}$ & $\begin{array}{l}65: 1 \\
74: 1 \\
81: 1 \\
84: 3 \\
91: 3\end{array}$ & $\begin{array}{l}79: 2 \\
83: 4 \\
90: 1\end{array}$ & $\begin{array}{l}74: 1 \\
81: 1 \\
84: 2 \\
92: 1\end{array}$ \\
\hline United States & $\begin{array}{l}73: 2 \\
80: 1 \\
81: 1 \\
90: 2 \\
92: 4\end{array}$ & $\begin{array}{l}70: 1 \\
75: 1 \\
80: 3 \\
82: 1 \\
91: 1\end{array}$ & $\begin{array}{l}73: 4 \\
80: 1 \\
90: 3\end{array}$ & $\begin{array}{l}70: 4 \\
75: 1 \\
82: 4 \\
91: 1\end{array}$ \\
\hline
\end{tabular}

* Reference dating corresponds to the NBER dating for the United States and to the dating proposed by Artis et al. (1997) for France and the United Kingdom.

Table 5. Business cycle characteristics of the $\log$ of the real GDP series

\begin{tabular}{llllll}
\hline \hline Country & $\begin{array}{l}\text { Number } \\
\text { of peaks }\end{array}$ & $\begin{array}{l}\text { Mean length } \\
\text { of expansion }\end{array}$ & $\begin{array}{l}\text { Mean length } \\
\text { of recession }\end{array}$ & $\begin{array}{l}\text { Mean amplitude } \\
\text { of expansion }\end{array}$ & $\begin{array}{l}\text { Mean amplitude } \\
\text { of recession }\end{array}$ \\
\hline United Kingdom 5 & $17.00(5.62)$ & $4.00(0.94)$ & $0.18(0.05)$ & $0.02(0.003)$ \\
United States 5 & $21.25(3.44)$ & $5.00(1.28)$ & $0.16(0.04)$ & $0.02(0.01)$ \\
\hline
\end{tabular}

Standard errors in parenthesis.

Artis et al. (1997) consider Industrial Production for a different period, define cycles period running between two peaks, and use a more complex dating algorithm. So, the small differences could be justified and do not lead to a rejection of our dating algorithm.

Table 5 gathers the business cycle characteristics of the series. We notice that in both countries, 5 major cycles occurred during the last 40 years. It also turns out that the expansions are longer and deeper than recessions. This stylized fact is generally acknowledged for classical cycles.

We start our empirical application by estimating different ARFIMA(p, d, q) models like (3). We use the Sowell's (1992) procedure of estimating by maximum likelihood in the time domain, taking values of $\mathrm{p}$ and $\mathrm{q}$ smaller than or equal to 3 . This procedure consistently estimates $d$ and the other parameters in the model when $d<0.5$ Thus, in order to assure stationarity we estimate the models in second differences, adding then two to the resulting values to obtain estimates of $d{ }^{10}$ Across the sixteen potential models, we choose the best one according to the Bayesian Information Criteria (BIC). The results are given in Table 6 .

We see that the best model specifications are an $\operatorname{ARFIMA}(1,1.38,2)$ for the UK and an $\operatorname{ARFIMA}(0,1.36,0)$ for the US. Thus, the orders of

\footnotetext{
${ }^{10}$ The estimates were also calculated based on first differences and they were, for some $\operatorname{ARMA}(p, q)$ components, equal to 0.49 , suggesting that second differences is more appropriate to assure stationarity.
} 


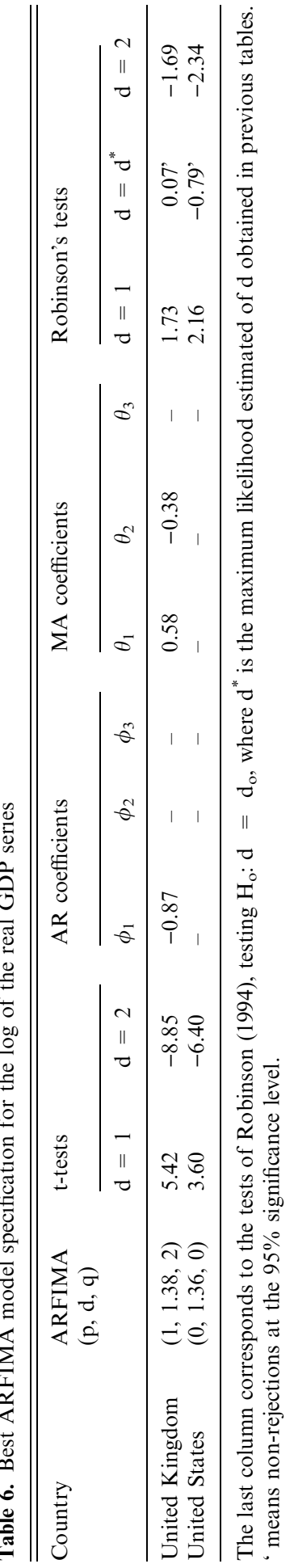


Table 7.

\begin{tabular}{|c|c|c|c|c|c|c|c|}
\hline \multirow[t]{2}{*}{ Country } & \multirow{2}{*}{$\begin{array}{l}\text { ARIMA } \\
(p, d, q)\end{array}$} & \multicolumn{3}{|c|}{ AR coefficients } & \multicolumn{3}{|c|}{ MA coefficients } \\
\hline & & $\phi_{1}$ & $\phi_{2}$ & $\phi_{3}$ & $\theta_{1}$ & $\theta_{2}$ & $\theta_{3}$ \\
\hline \multicolumn{8}{|c|}{ Best ARI(1)MA model specifications for the log of the real GDP } \\
\hline United Kingdom & $(1,1,2)$ & 0.95 & - & - & -0.90 & 0.10 & - \\
\hline United States & $(1,1,1)$ & 0.95 & - & - & -0.63 & - & - \\
\hline \multicolumn{8}{|c|}{ Best ARI(2)MA model specifications for the log of the real GDP } \\
\hline United Kingdom & $(0,2,1)$ & - & - & - & -0.99 & - & - \\
\hline United States & $(1,2,1)$ & 0.30 & - & - & -0.98 & - & - \\
\hline
\end{tabular}

integration are in all cases higher than one but smaller than two, and the t-statistics based on the nulls $d=1$ and $d=2$ reject both hypotheses for the two series. (Note that the estimates are based on maximum likelihood and thus, standard tests based on the statistics $(\mathrm{d}-1) / \mathrm{SE}(\mathrm{d})$ and $(\mathrm{d}-2) / \mathrm{SE}(\mathrm{d})$ are applicable in these cases). As a validation control for each of the selected models, we use the tests of Robinson (1994). We report, in the last columns of Table 6 , the results of $\hat{r}$ in (5) in a model given by (1), testing $H_{o}$ (4) for values $d_{\mathrm{o}}=1, d^{*}$ and 2 , where $\mathrm{d}^{*}$ is the chosen value according to the previous estimation procedure. ${ }^{11}$ Note that the non-rejection of $\mathrm{H}_{\mathrm{o}}(4)$ in these cases will imply that the series follow respectively an I(1), an ARFIMA, and an I(2) process. The most interesting feature observed in these results is that $\mathrm{H}_{\mathrm{o}}$ (4) cannot be rejected in any series when $d_{o}$ is chosen as the estimated value with the previous model selection criterion, indicating that the models can be correctly specified with the ARFIMA models.

In order to have a more convincing evidence in favour of fractional orders of integration, Table 7 firstly reports the results of ARIMA models imposing $d=1$ in the GDP series. The best model specifications appear to be then an $\operatorname{ARIMA}(1,1,2)$ for the UK, and an $\operatorname{ARIMA}(1,1,1)$ for USA. However, we observe that in both cases, the AR parameter is very close to the unit root case (0.95) and such an hypothesis cannot statistically be rejected at the $95 \%$ significant level. Thus we also report the results assuming that $d=2$. In this context, the best model specifications, according to the BIC, are an $\operatorname{ARIMA}(0,2,1)$ for UK and an $\operatorname{ARIMA}(1,2,1)$ for USA and in both cases the roots of the MA part seems to indicate now that there is a common unit root in the process. In view of these cancelling roots, a model with a single unit root would be preferred. However, another look at the results of Robinson's (1994) tests in the last three columns of Table 6 suggests that a fractional model is preferred since the null hypothesis of $\mathrm{H}_{\mathrm{o}}: d=1$ is in both series rejected in favour of alternatives of form: $d>1$, while the null of $d=2$ is rejected against $d<2$. Also, the evidence against the unit root is stronger for the US than for the UK. Then, it becomes apparent that the ARFIMA models presented in Table 6 may better describe the long run behaviour of the two series since it does not restrict themselves to the integer differencing of the series. To show this, we describe in the following section simulated business

\footnotetext{
${ }^{11}$ The null hypothesis $H_{o}$ (4) in the tests of Robinson (1994) considers $d_{o}$ as any given real value and thus, we can test $\mathrm{H}_{\mathrm{o}}: d=d^{*}$, taking $d^{*}$ as a given value rather than as an estimated one.
} 
Table 8.

\begin{tabular}{|c|c|c|c|c|c|}
\hline Country & $\begin{array}{l}\text { Aver. } \\
\text { number } \\
\text { of peaks }\end{array}$ & $\begin{array}{l}\text { Mean length } \\
\text { of expansion }\end{array}$ & $\begin{array}{l}\text { Mean length } \\
\text { of recession }\end{array}$ & $\begin{array}{l}\text { Mean } \\
\text { amplitude of } \\
\text { expansion }\end{array}$ & $\begin{array}{l}\text { Mean } \\
\text { amplitude of } \\
\text { recession }\end{array}$ \\
\hline \multicolumn{6}{|c|}{ Simulated business cycle characteristics of the log of the real GDP series with ARFIMA MODELS } \\
\hline United Kingdom & $\begin{array}{l}5 \\
(0.0446)\end{array}$ & $\begin{array}{l}22.8476 \\
(4.7520)\end{array}$ & $\begin{array}{l}16.0179 \\
(4.752)\end{array}$ & $\begin{array}{l}0.0803 \\
(0.0234)\end{array}$ & $\begin{array}{l}0.0685 \\
(0.023)\end{array}$ \\
\hline United States & $\begin{array}{l}9 \\
(0.0761)\end{array}$ & $\begin{array}{l}13.6392 \\
(2.7195)\end{array}$ & $\begin{array}{l}8.8280 \\
(2.4950)\end{array}$ & $\begin{array}{l}0.0294 \\
(0.0101)\end{array}$ & $\begin{array}{l}0.0237 \\
(0.0089)\end{array}$ \\
\hline \multicolumn{6}{|c|}{$\begin{array}{l}\text { Simulated business cycle characteristics of the log of the real GDP series } \\
\text { with } A R I(2) M A M O D E L S\end{array}$} \\
\hline United Kingdom & $\begin{array}{l}3 \\
(0.033)\end{array}$ & $\begin{array}{l}24.066 \\
(3.800)\end{array}$ & $\begin{array}{l}16.031 \\
(3.760)\end{array}$ & $\begin{array}{l}0.4389 \\
(0.0971)\end{array}$ & $\begin{array}{l}0.314 \\
(0.090)\end{array}$ \\
\hline United States & $\begin{array}{l}3 \\
(0.035)\end{array}$ & $\begin{array}{l}27.423 \\
(4.215)\end{array}$ & $\begin{array}{l}16.9742 \\
(3.875)\end{array}$ & $\begin{array}{l}0.2502 \\
(0.056)\end{array}$ & $\begin{array}{l}0.1707 \\
(0.051)\end{array}$ \\
\hline \multicolumn{6}{|c|}{$\begin{array}{l}\text { Simulated business cycle characteristics of the log of the real GDP series } \\
\text { with ARI(1)MA MODELS }\end{array}$} \\
\hline United Kingdom & $\begin{array}{l}12 \\
(0.1040)\end{array}$ & $\begin{array}{l}9.902 \\
(1.123)\end{array}$ & $\begin{array}{l}5.902 \\
(1.112)\end{array}$ & $\begin{array}{l}0.023 \\
(0.004)\end{array}$ & $\begin{array}{l}0.023 \\
(0.004)\end{array}$ \\
\hline United States & $\begin{array}{l}12 \\
(0.1040)\end{array}$ & $\begin{array}{l}9.617 \\
(1.170)\end{array}$ & $\begin{array}{l}5.865 \\
(1.089)\end{array}$ & $\begin{array}{l}0.005 \\
(0.001)\end{array}$ & $\begin{array}{l}0.006 \\
(0.001)\end{array}$ \\
\hline
\end{tabular}

cycle characteristics based on both, the ARFIMA models described in Table 5 and the ARI(1)MA, ARI(2)MA models of Table 7.

\section{A simulated comparison between ARIMA and ARFIMA models}

Once the coefficients of the ARI(1)MA, ARI(2)MA and ARFIMA models have been estimated, our objective now consists of selecting the best model, with respect to its ability to reproduce the business cycles features. So, we simulate 2500 ARI(1)MA, ARI(2)MA and ARFIMA models for each country and compute their business cycle characteristics. Their empirical mean and variance are indicated in Table 8 .

The selection of the best model stems out from the comparison with the observed features in Table 5. It is first noticeable that Table 8 confirms the results exhibited in Sect. 3: As the degree of fractional integration is always lower than 2, the number of peaks is lower in the cases of ARI(2)MA models, whereas the contrary results hold for the lengths and the amplitudes. Furthermore, it also turns out that the increase in the amplitude of expansion and recession is much higher than the decrease in the number of peaks. Opposite results are obtained if we considered the ARFIMA vs the ARI(1)MA model. Such a result also corroborates the theoretical findings reported in Tables 1-3 even if they are not fully comparable as the process we consider now has a MA and AR parts. Nevertheless, considering the business cycle characteristics for a fractional process with $\mathrm{AR}(1)$ disturbances, $\phi=0.75$ and a sample size of 300 (namely the bottom of Table 2), it turns out that the number of peaks, the mean length of recession and expansion are comparable to those found for US and UK in the empirical case (for example for the ARFIMA $(d=1.36)$ in the US the number of peaks is 9 whereas it has an average value 
of 6.42 in the theoretical simulations with $d=1.5$ ). The comparison is difficult for the amplitudes as the simulations in Tables $1-3$ are performed with a unit variance, whereas we keep the estimated variance for the empirical study. Nevertheless the sign of the changes between ARI(1)MA, ARI(2)MA and ARFIMA is similar (the amplitude increases with the degree of fractional integration). ${ }^{12}$

In the case of the UK, the ARFIMA model leads to a better replication of the features: the number of peaks corresponds to what is observed (5 cycles) and the amplitudes (of both phase of the cycle) are closer to the historical observations. Both length features are also bettered but not too significantly. For the US, the ARFIMA model slightly overestimates the number of peaks (9) whereas the ARI(2)MA underestimates it (3), and the ARI(1)MA largely overestimate it (12). Nevertheless, we notice that the length features and the mean amplitude of the recession are more in line with the observed features. Only the mean amplitude of expansion is underestimated by the ARFIMA model, compared to the ARI(2)MA. This result is probably due to the linearity of the models: ARI(2)MA models exhibit mean amplitude features corresponding to the observed expansion amplitude (0.18) and so overestimate recession amplitude, whereas ARFIMA models replicate amplitude of the recession (0.02) and so overestimate the expansion amplitude. However, the ARFIMA model appears here slightly better than the ARI(2)MA one. In conclusion, it appears that the ARFIMA models perform better than the ARIMAs, to reproduce the major business cycle features.

\section{Conclusions}

We have tried in this article to analyse how fractionally integrated models can modify the reproduction of business cycle features. From a theoretical point of view, several Monte Carlo experiments conducted via simulations showed that the business cycle features can be seriously affected by the degree of integration of the series as well as by the short run (ARMA) components associated to it. We built up five indicators for the business cycle characteristics, namely, the number of peaks, and the length and amplitude of the recessions and of the expansions. It turns out that the average number of cycles increases until $d \sim 0.5$, and then sharply decreases. The other features share a symmetric pattern. The importance of the stochastic trend part of the process (when $d>0.5$ ) justifies this result. Next, we modelled the real GDP series in the UK and the US by means of fractionally ARIMA (ARFIMA) models. We used the Sowell's (1992) procedure of estimating by maximum likelihood in the time domain. The results indicate that the series can be specified in terms of ARFIMA models, with orders of integration higher than one but smaller than two. This is also corroborated by the tests of Robinson (1994), which are the most efficient ones when directed against the appropriate (fractional) alternatives. When imposing an integer order of differencing, the series appear to be I(2), and comparing the ARFIMA models with

\footnotetext{
${ }^{12}$ In fact, as noticed by an anonymous referee, the comparison of the business cycle features (especially the number of peaks, with the simulation results (Tables 1-3) confirm ex-post that for both countries the degree of fractional integration lies between 1 and 1.5.
} 
the ARI(1)MA and ARI(2)MA ones, the former models seem to better describe the main business cycle characteristics of the data. Hess and Iwata (1997) showed that the ARIMA models better replicate the business cycle features of many historical data compared with other approaches and, in that respect, we have shown in this article that the ARFIMA specification can do it even better than the ARIMA model.

\section{References}

Adenstedt RK (1974) On large sample estimation for the mean of a stationary random sequence, Annals of Statistics 2:1095-1107

Artis M, Osborn D, Kontolemnis. Z (1997) Classical business cycles for G7 and European countries. Journal of Business 70:249-281

Beaudry P, Koop G (1993) Do recessions permanently change output? Journal of Monetary Economics 31:149-163

Blanchard OJ (1981) What is left on the multiplier accelerator? American Economic Review Proceedings 71:150-154

Box GEP, Jenkins GM (1970) Time series analysis, forecasting and control. Holden Day, San Francisco

Burns A, Mitchel W (1947) Measuring business cycles. NBER, New York

Bry G, Boschan C (1971) Cyclical analysis of time series: Selected procedures and computer programs,. NBER, New York

Campbell JH, Mankiw NG (1987) Are output fluctuations transitory. Quarterly Journal of Economics 102:857-880

Canova F (1994) Detrending and turning points. European Economic Review 38:614-623

Candelon B, Hénin PY (1995) La récession des années quatre-vingt dix a-t-elle été exceptionnelle? Economie et Prévision 120:51-71

Chambers M (1998) Long memory and aggregation in macroeconomic time series,. International Economic Review 39:1053-1072

Clark PK (1987) The cyclical component of US economic activity. Quarterly Journal of Economics 102:798-814

Croczeck-Georges R, Mandelbrot BB (1995) A class of micropulses and anti-persistent fractional Brownian motion. Stochastic Processes and Their Applications 60:1-18

Dahlhaus R (1989) Efficient parameter estimation for self-similar processes. Anals of Statistics 17:1749-1766

Diebold FX, Nerlove N (1989) Unit roots in economic time series: A selective survey. Advanced in Econometrics 8:3-69

Diebold FX, Rudebusch GD (1989) Long memory and persistence in aggregate output. Journal of Monetary Economics 24:189-209

Diebold FX, Rudebusch GD (1992) Have the postwar economic fluctuation been stabilized? American Economic Review 82:993-1005

Doornik JA, Ooms M (1999) A package for estimating, forecasting and simulating ARFIMA models: Arfima package 1.0 for OX. www.nuff.ox.ac.uk/Users/Doornik/Oxford

Fox R, Taqqu M (1986) Large sample properties of parameters estimates for strongly dependent stationary Gaussioan time series. Annals of Statistics 14:517-532

Gil-Alana LA (1999) Testing fractional integration with monthly data. Economic Modelling 16:613-629

Gil-Alana LA (2000) Mean reversion in the real exchange rates. Economics Letters 69:285-288

Gil-Alana LA (2001) Testing stochastic cycles in macroeconomic time series. Journal of Time Series Analysis 22:411-430

Gil-Alana LA, Robinson PM (1997) Testing of unit roots and other nonstationary hypotheses in macroeconomic time series. Journal of Econometrics 80:241-268

Gil-Alana LA, Robinson PM (2001) Testing seasonal fractional integration in the UK and Japanese consumption and income. Journal of Applied Econometrics 16:95-114

Granger CWJ (1980) Long memory relationships and the aggregation of dynamic models. Journal of Econometrics 14:227-238 
Granger CWJ (1981) Some properties of time series data and their use in econometric model specification. Journal of Econometrics 16:121-130

Hamilton JD (1989) A new approach to the economic analysis of non-stationary time series and the business cycle. Econometrica 57:357-384

Hauser MA (1999) Maximum likelihood estimators for ARFIMA models: A Monte Carlo study. Journal of Statistical Planning and Inference 80:229-255

Hess GD, Iwata S (1997) Measuring and comparing business cycle features. Journal of Business Economics and Statistics 15(4):432-444

Hosking JRM (1981) Modelling persistence in hydrological time series using fractional differencing. Water Resources Research 20:1898-1908

Lam PS (1990) The Hamilton model with a general autoregressive component. Journal of Monetary Economics 26:409-432

Lippi M, Zaffaroni P (1999) Contemporaneous aggregation of linear dynamic models in large economies. Manuscript, Research Department, Bank of Italy

McNess SK (1991) Forecasting cyclical turning points. The lessons of the last three recessions. In Lahiri K, Moore GH (eds) Leading economic indicators Cambridge University Press, Cambridge, pp 151-168

Michelacci C, Zaffaroni P (2000) (Fractional) Beta convergence. Journal of Monetary Economics 45:129-153

Moore G, Zarnowitz V (1982) Sequential signals of recession and recovery. Journal of Business 55:57-85

Neftçi SN (1984) Are economic time series asymmetric over the business cycle? Journal of Political Economy 92:307-328

Nelson CR, Plosser CI (1982) Trends and random walks in macroeconomic time series. Journal of Monetary Economics 10:139-162

Pagan AR, Harding D (1999) Dissecting the cycle: A methodological investigation. Melbourne Institute Working Paper, University of Melbourne

Parke WR (1999) What is fractional integration? Review of Economics and Statistics 81:632-638

Perron P (1989) The great crash, the oil hock and the unit root hypothesis. Econometrica 77:1361-1401

Robinson PM (1978) Statistical inference for a random coefficient autoregressive model. Scandinavian Journal of Statistics 5:163-168

Robinson PM (1994) Efficient tests of nonstationary hypotheses. Journal of the American Statistical Association 89:1420-1437

Romer CD (1986) Is stabilization of the post-war economy a figment of the data? American Economic Review 76:314-334

Romer CD (1994) Remeasuring business cycles. Journal of Economic History 54:573-609

Silverberg G, Verspagen B (1999) Long memory in time series of economic growth and convergence. Eindhoven Centre for Innovation Studies, Working Paper 99.8

Sowell F (1992) Modelling long run behaviour with the fractional ARIMA model. Journal of Monetary Economics 29:277-302

Smith J, Taylor N, Yadav S (1997) Comparing the bias and misspecification in ARFIMA models. Journal of Time Series Analysis 18:507-527

Stock JH, Watson MW (1986) Does GNP have a unit root? Economics Letters 22:147-151

Taqqu MS (1975) Weak convergence to fractional Brownian motion and to the Rosenblatt process. Z. Wahrscheinlichkeitstheorie verw. Geb. 31:287-302

Taqqu MS, Willinger W, Sherman R (1997) Proof of a fundamental result in self-similar traffic modelling. Computer communication Review 27:5-23

Watson MW (1994) Business-cycle durations and postwar stabilization of the U.S. economy, American Economic Review 84:24-46

Webb R (1991) On predicting stages of business cycles. In: Lahiri K, Moore G (eds) Leading economic indicators: New approaches and forecasting record Cambridge University Press Cambridge, pp 129-140 